\title{
Secondary Postpartum Haemorrhage following vaginal delivery - a 3-year survey of causes and management
}

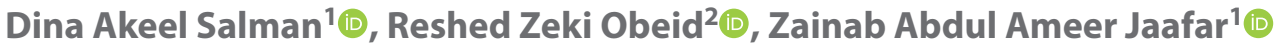 \\ ${ }^{1}$ Department of Obstetrics and Gynecology, College of Medicine, Al-Mustansiriya University, Baghdad, Iraq \\ 2Department of Obstetrics and Gynecology, College of Medicine, Al-Anbar University, Al-Anbar, Iraq
}

\begin{abstract}
Objectives: Secondary postpartum haemorrhage (PPH) is a serious complication of childbirth and a life-threatening condition that may lead to infertility amongst women during the reproductive age groups.

The objective of this study is to highlight the underlying causes of secondary PPH and outcomes for patients who delivered vaginally, with the aim of reducing maternal mortality and morbidity.

Material and Methods: This is a prospective cohort study conducted in the Department of Obstetrics and Gynaecology at AL-Yarmouk Teaching Hospital, Baghdad, Iraq. The study was conducted over a 3-year period from December 2015 to December 2018. Women who delivered vaginally with a gestational age of at least 24 weeks, with no previous caesarean or uterine scars, who were admitted to the hospital complaining of bleeding from their genital tracts after 24 hours of delivery, but prior to 6 weeks from delivery, were enrolled in the study. Patients received resuscitative measures and medical treatment and were observed regarding their response to medical treatment and whether they required surgical intervention. Types of management were also evaluated, and histopathological reviews were gathered and recorded for those who needed retained pieces of product evacuated or hysterectomies.

Results: Two hundred cases were analysed; the incidence of severe secondary postpartum haemorrhage was 60 per 10,000 deliveries. Endometritis was the leading cause (64\% of patients), followed by retained placental pieces (13.5\%); emergency hysterectomy was performed in $34.5 \%$ of patients. This study is novel because it is the first to shed light on secondary postpartum haemorrhage in unscarred uteri in Iraq.

Conclusions: Endometritis was the most common cause of secondary postpartum haemorrhage, and emergency hysterectomy was the most common strategy of treatment.
\end{abstract}

Key words: secondary postpartum haemorrhage; caesarean section; hysterectomy; endometritis

Ginekologia Polska 2020; 91, 10: 607-612

\section{INTRODUCTION}

Complications of pregnancy and childbirth have been one of the leading causes of death and disability among women of reproductive age [1]. Postpartum haemorrhage (PPH) is an unusual complication following a vaginal delivery with an incidence of about $4 \%$ of all deliveries; it contributes to one-third of maternal mortalities in developing countries [2]. Secondary postpartum haemorrhage is any significant bleeding from a genital tract by any route (intra-abdominal or vaginal) that commences after the first 24 hours following delivery until the $6^{\text {th }}$ weeks of puerperium. Because the estimated blood loss is difficult to assess, the diagnosis depends on the clinical evaluation of the patient [3]. The presentation varies from mild spotting or excessive lochia, which can be managed by medical treatment, to severe life-threating bleeding that requires surgical removal of a retained piece of tissue or a lifesaving hysterectomy to stop the bleeding and save the life of the mother [4]. The most common etiological factors are retaining a piece of placenta, endometritis, sub involution of placental bed, pseudoaneurysm of the uterine artery, arteriovenous malformation, dehiscent of the uterine scar and, rarely, gestational trophoblastic disease (GTD) [5]. Complications and consequences of secondary postpartum haemorrhage have importance to the researcher for assessing risks factors and preventive method spatially the alarming outcome of secondary PPH and subsequent effect in further fertility [6].

\section{The aim of the study}

The objective of this study is to evaluate the underlying causes of secondary PPH and the outcomes for patients. 


\section{MATERIAL AND METHODS}

This is a prospective cohort study that was done at the Department of Obstetrics and Gynaecology of ALYarmouk Teaching Hospital, Baghdad, Iraq. The study was conducted over a 3 year period from December 2015 to December 2018. The study protocol was approved by the Ethics Committee of the Medical College at Al-Mustansiriyah University, Iraq. Verbal consents were received from all participants.

\section{Inclusion criteria}

Women of any age who delivered vaginally with a gestational age of at least 24 weeks who were admitted to the hospital after 24 hours of delivery, but prior to 6 weeks from delivery, with complaints of heavy bleeding or with a history of repetitive attacks of irregular vaginal bleeding with unstable vital signs or with a drop in haemoglobin levels were enrolled in the study.

\section{Exclusion criteria}

All patients with prior scars, with previous uterine surgery, presenting with primary $\mathrm{PPH}$, or presenting with placenta previa and accrete syndrome were excluded from the study.

A full history was obtained including age, parity, residence, educational level, modes of previous deliveries, intervals between pregnancies, history of medical diseases such as hypertension and diabetes mellitus, and gestational age. Place of delivery, time of presentations and any primary post-partum bleeding and amount of bleeding were also recorded. We conducted a systemic and local examination of each patient, including vital signs. Investigations included complete blood count, liver and renal function test, and high vaginal swab that was sent for culture and sensitivity. Ultrasounds were performed on all patients, and abnormalities were identified, such as retained pieces of product. All the patients received intravenous fluid, oxytocic drugs, tranexamic acid, blood and/or blood products and broad-spectrum antibiotics of the same type based the hospital's protocol, which includes clindamycin $900 \mathrm{mg}$ three times per day and Garamycin (Gentamicin) $20 \mathrm{mg} / \mathrm{kg}$ per dose. Thereafter, each patient was observed regarding her response to medical treatment and whether she required surgical intervention. Additionally, histopathological specimens were sent for examination for cases of retained pieces of placenta and hysterectomy cases, and the records were collected and recorded.

\section{Statistical analysis}

Statistical Package for Social Sciences (SPSS version $25)^{*}$ was used for data analysis. Categorical data were represented by frequencies and percentages. Associations

\begin{tabular}{|c|c|c|c|}
\hline \multicolumn{2}{|l|}{ Variable } & No. (200) & $\%$ \\
\hline \multirow{4}{*}{ Age (years) } & $<20$ years & 37 & $18.5 \%$ \\
\hline & $20-29$ years & 65 & $32.5 \%$ \\
\hline & $30-39$ years & 83 & $41.5 \%$ \\
\hline & $40+$ years & 15 & $7.5 \%$ \\
\hline \multirow{2}{*}{$\begin{array}{l}\text { Area of } \\
\text { residence }\end{array}$} & Urban & 92 & $46 \%$ \\
\hline & Rural & 108 & $54 \%$ \\
\hline \multirow{4}{*}{ Education } & Illiterate & 59 & $29.5 \%$ \\
\hline & Primary & 73 & $36.5 \%$ \\
\hline & Secondary & 30 & $15 \%$ \\
\hline & College \& Higher & 38 & $19 \%$ \\
\hline \multirow{3}{*}{$\begin{array}{l}\mathrm{BMI}\left(\mathrm{Kg} / \mathrm{m}^{2}\right) \\
\text { at the time of } \\
\text { presentation }\end{array}$} & Normal (18.5-24.9) & 55 & $27.5 \%$ \\
\hline & Overweight (25.0-29.9) & 51 & $25.5 \%$ \\
\hline & Obese $(=>30.0)$ & 94 & $47 \%$ \\
\hline
\end{tabular}

between variables were measured using Pearson's Chisquare test. Results were considered statistically significant when the $p$-value equal to or less than 0.05 .

*IBM Corp. Released in 2017. IBM SPSS Statistics for Windows, Version 25.0. Armonk, NY: IBM Corp

\section{RESULTS}

During the study period, there were 33,000 live births in the Al-Yarmouk teaching hospital, which covers a wide area of Baghdad. The total number of vaginal deliveries was $17,830(55 \%)$ while the total number of CS was 15,170 (45\%). Two hundred patients were identified with severe secondary $\mathrm{PPH}$ following vaginal deliveries and required admission to the hospital, and the incidence was $6 \%$. Of the study group, 83 (41.5\%) were 30-39 years old, 108 (54\%) were living in a rural area, more than one-third had primary school education and less than one-fifth had higher education. Most of the patients (47\%) were obese (Tab. 1).

About 90 (45\%) of women in the study group has a parity of 2-4. The babies delivered between 36-38 were 98 (49\%). About 121 (60.5\%) of the patients had no antenatal care. The most frequent medical disease during the index pregnancy was a history of anaemia, found in 87 women (43.5\%). About three-quarters - 149 (74.5\%) — of the patients delivered in a hospital (whether our hospital or other hospitals). The onset of labour was spontaneous for $64 \%$ of study participants and induced for the remaining $36 \%$. Prolonged labour was found in 87 (43.5\%) of the patients and birth weight greater than $4 \mathrm{~kg}$ was found in 97 (48.5\%) of the patients (Tab. 2).

The induction of labour was performed most frequently for premature pre-labour rupture of membrane (PPROM) (29.2\%) or postdate pregnancy (25\%) (Fig. 1). 


\begin{tabular}{|c|c|c|c|}
\hline \multicolumn{2}{|l|}{ Variable } & No. (200) & $\%$ \\
\hline \multirow{3}{*}{ Parity } & 1 & 78 & $39 \%$ \\
\hline & $2-4$ & 90 & $45 \%$ \\
\hline & $\geq 5$ & 32 & $16 \%$ \\
\hline \multirow{3}{*}{$\begin{array}{l}\text { Gestational } \\
\text { age }\end{array}$} & Less than 35 & 29 & $14.5 \%$ \\
\hline & $\geq 36-38$ & 98 & $49 \%$ \\
\hline & $\geq 39-41$ & 73 & $36.5 \%$ \\
\hline \multirow{3}{*}{$\begin{array}{l}\text { Inter- } \\
\text {-pregnancy } \\
\text { interval } \\
\text { (years) }\end{array}$} & One & 95 & $47.5 \%$ \\
\hline & Two & 76 & $38 \%$ \\
\hline & More than 3 & 29 & $14.5 \%$ \\
\hline \multirow{2}{*}{$\begin{array}{l}\text { Antenatal } \\
\text { care (ANC) }\end{array}$} & Yes & 79 & $39.5 \%$ \\
\hline & No & 121 & $60.5 \%$ \\
\hline \multirow{4}{*}{$\begin{array}{l}\text { Medical } \\
\text { disease } \\
\text { during } \\
\text { pregnancy }\end{array}$} & Anaemia & 87 & $43.5 \%$ \\
\hline & Hypertensive disorder & 8 & $4 \%$ \\
\hline & Diabetes mellitus & 9 & $4.5 \%$ \\
\hline & Coagulation disorder & 5 & $2.5 \%$ \\
\hline \multirow{2}{*}{$\begin{array}{l}\text { Place of } \\
\text { delivery }\end{array}$} & Hospital & 149 & $74.5 \%$ \\
\hline & Home delivery & 51 & $25.5 \%$ \\
\hline \multirow{2}{*}{$\begin{array}{l}\text { Onset of } \\
\text { labour }\end{array}$} & Spontaneous & 128 & $64 \%$ \\
\hline & Induced & 72 & $36 \%$ \\
\hline \multicolumn{2}{|c|}{ Prolonged labour } & 87 & $43.5 \%$ \\
\hline \multirow{3}{*}{$\begin{array}{l}\text { Birth weight } \\
\text { (Kg) }\end{array}$} & $<2.5$ & 21 & $10.5 \%$ \\
\hline & $2.5-4$ & 82 & $41 \%$ \\
\hline & $>4$ & 97 & $48.5 \%$ \\
\hline
\end{tabular}

Time of presentation after delivery varied and $44.5 \%$ presented 6-10 days following delivery. Nearly half of the patients (45.5\%) had a history of primary PPH. PROM was found in 57 (28.5\%) cases. On admission, 147 (73.5\%) presented with shock, while 159 (79.5\%) patients had a fever. On admission, maternal haemoglobin less than 7 was seen in 105 patients (52.5\%). Hospitalization more than 5 days needed in 98 (49\%). Readmission observed in 94 (47\%) (Tab. 2).

All patients needed a transfusion of blood, blood product Factor VII and 149 (74.5\%) needed a massive blood transfusion, ( $\geq 10$ red blood units within $24 \mathrm{~h}$, the transfusion of $>4$ red blood units in $1 \mathrm{~h}$ ) [7]. Additionally, 33 (16.5\%) of cases responded to medical treatment (including Oxytocic drugs, antibiotics, tranexamic acid blood and or blood products and factor VII).

Vaginal exploration was done for the patients, which included removal of retained products of conception for $27(13.5 \%)$, suturing of cervical tears for $18(9 \%)$ and uterine balloon for 2 (1\%). Laparotomies with the conservative of the uterus, including $B$ lynch and internal iliac artery ligation, were required in $20(10 \%)$ and 12 (6\%) needed their ruptured uterus repaired. Emergency transabdominal hysterectomy without salpingo-oophorectomy was performed on 69 (34.5\%) of the patients, and 19 (9.5\%) need hysterectomy with internal iliac artery ligation. The major reason for performing a hysterectomy was the inability to stop bleeding using more conservative methods. All the specimens of the uterus and retained pieces of product

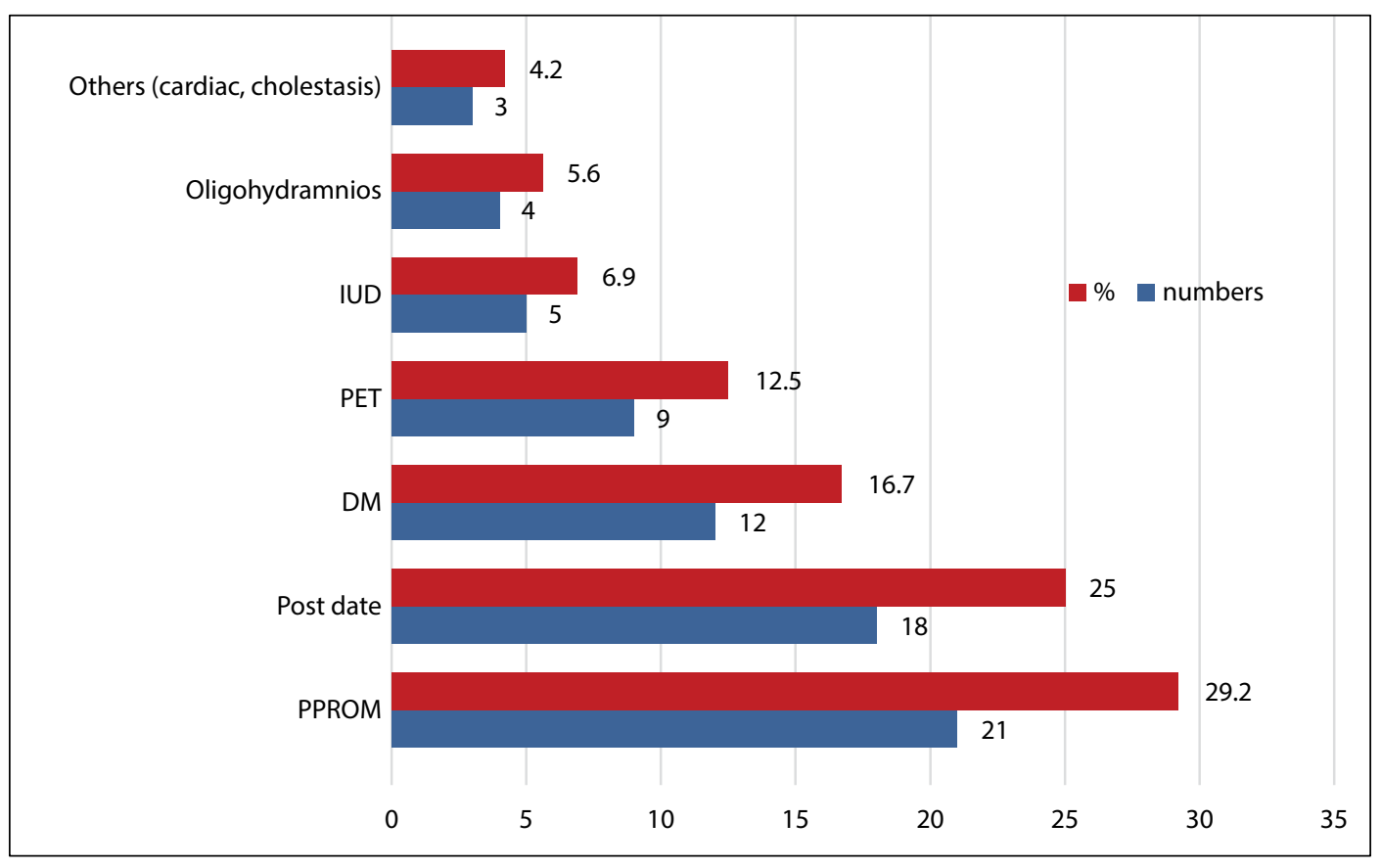

Figure 1. The indication of induction of labour 


\begin{tabular}{l|l|l|l|}
\hline \multicolumn{4}{l}{ Table 3. Clinical evaluation at the time of admission } \\
\hline Variable & & No.(200) & $\%$ \\
\hline & $1-5$ & 66 & $33 \%$ \\
\hline $\begin{array}{l}\text { Time of presentation } \\
\text { after delivery (days) }\end{array}$ & $6-10$ & 89 & $44.5 \%$ \\
\hline History of primary PPH & $10-20$ & 27 & $13.5 \%$ \\
\hline History of PROM & $20-42$ & 18 & $9 \%$ \\
\hline Signs and symptoms & Shock & 147 & $45.5 \%$ \\
\hline Maternal haemoglobin & Fever & 159 & $73.5 \%$ \\
\hline on admission & Less than 7 & 105 & $52.5 \%$ \\
\hline Hospitalization more than 5 days & 98 & $49 \%$ \\
\hline Readmission & & 94 & $47 \%$ \\
\hline
\end{tabular}

were sent for histopathology. Admission to RCU was 8.5\% and the mortality rate was $1 \%$ (Tab. 3).

Endometritis was the leading cause of secondary PPH among the patients of this study (64\%), followed by retained placental pieces (13.5\%), 8\% was due to cervical or vaginal tears, $4.5 \%$ was related to uterine atony, ruptured uterus was found in $3.5 \%$ of cases, coagulation or haematological disease in $3 \%$, which was 4 cases of idiopathic thrombocytopenic purpura and 2 cases of Von Willebrand disease diseases, choriocarcinoma in $2.5 \%$ and the remaining $1 \%$ of cases had a different cause of the cause was not found (Fig. 2).

\begin{tabular}{|c|c|c|c|}
\hline \multicolumn{2}{|c|}{ Types of intervention } & Numbers & $\%$ \\
\hline \multicolumn{2}{|c|}{ Massive blood transfusion } & 149 & $74.5 \%$ \\
\hline \multicolumn{2}{|c|}{$\begin{array}{l}\text { Responded to conservative medical } \\
\text { treatment (antibiotics, blood and blood } \\
\text { product, factor } 7 \text {, tranexamic acid) }\end{array}$} & 33 & $16.5 \%$ \\
\hline \multirow{3}{*}{$\begin{array}{l}\text { Vaginal } \\
\text { exploration }\end{array}$} & $\begin{array}{l}\text { Removal of retained } \\
\text { products of conception }\end{array}$ & 27 & $13.5 \%$ \\
\hline & $\begin{array}{l}\text { Cervical and or vaginal } \\
\text { tears suturing }\end{array}$ & 18 & $9 \%$ \\
\hline & Uterine balloon & 2 & $1 \%$ \\
\hline \multirow{2}{*}{$\begin{array}{l}\text { Laparotomy } \\
\text { with the } \\
\text { conservation } \\
\text { of the uterus }\end{array}$} & $\begin{array}{l}\text { Repair of ruptured } \\
\text { uterus }\end{array}$ & 20 & $10 \%$ \\
\hline & $\begin{array}{l}\text { B lynch and internal } \\
\text { iliac artery ligation }\end{array}$ & 12 & $6 \%$ \\
\hline \multirow[b]{2}{*}{ Hysterectomy } & Hysterectomy only & 69 & $34.5 \%$ \\
\hline & $\begin{array}{l}\text { Hysterectomy with } \\
\text { internal iliac artery } \\
\text { ligation }\end{array}$ & 19 & $9.5 \%$ \\
\hline \multicolumn{2}{|c|}{ Admission to respiratory care unit } & 17 & $8.5 \%$ \\
\hline \multicolumn{2}{|l|}{ Mortality } & 2 & $1 \%$ \\
\hline
\end{tabular}

\section{DISCUSSION}

One of the most challenging conditions to manage in obstetrics is a postpartum haemorrhage, which is considered one of the most important causes of maternal death and morbidity worldwide [6]. Optimal management and saving the life of the mother depend on the early diagnosis of this condition. Many studies have attempted to shed light on the management options available; for example, BUL — BUL S et al. [8]

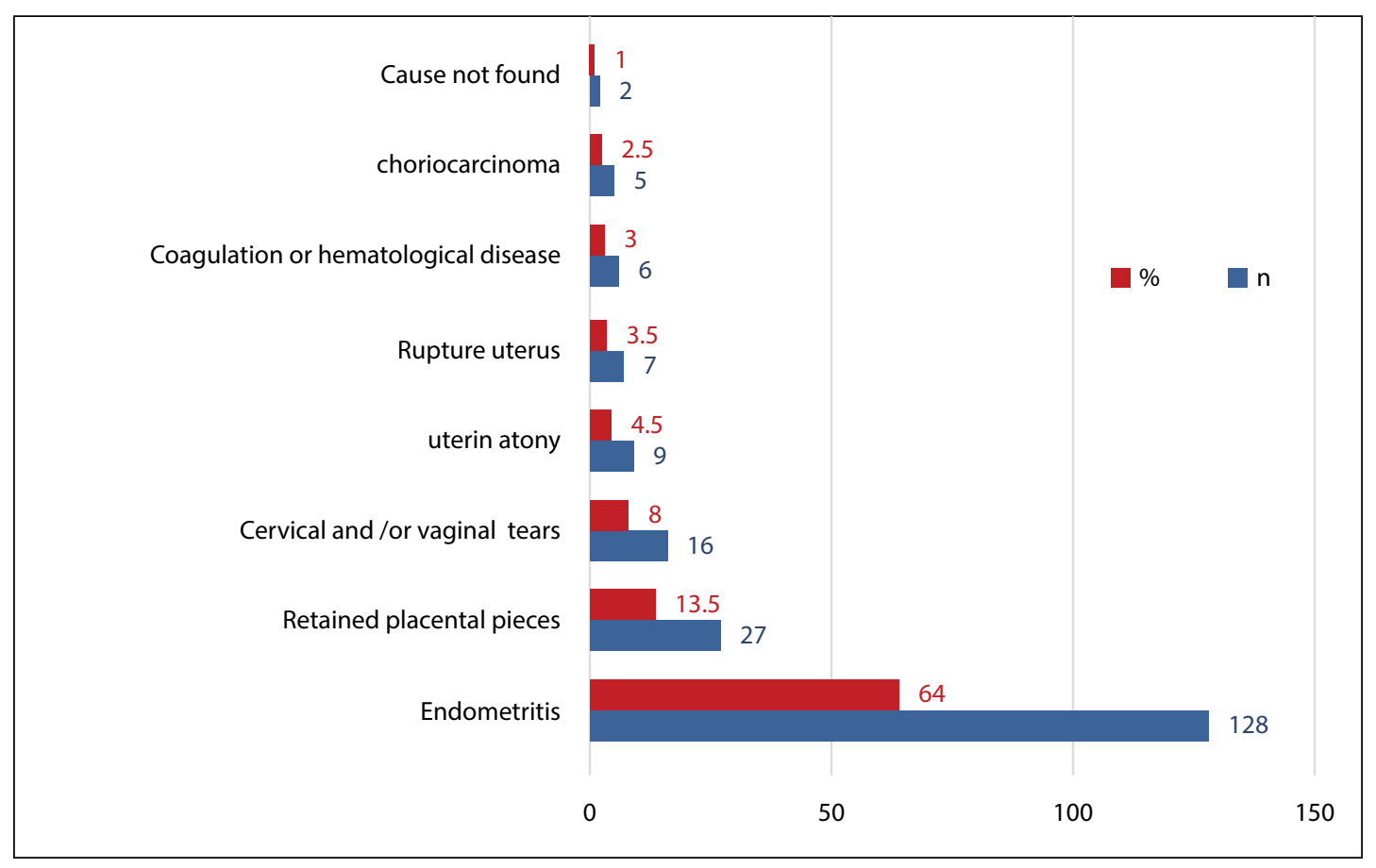

Figure 2. The causes of secondary PPH 
found that the highest age group for women who presented with PPH was between 30 to 35 years - which we also found in this study - perhaps due to the higher parity in this age group. Most of the patients admitted to AL-Yarmouk hospital were from rural areas, which is similar to the previous study by Carrole et al. [8]. This finding may be related to a deficiency of talent and difficulty in attainment health care centres. Moreover, we found that women with BMls of more than $30 \mathrm{Kg} / \mathrm{m}^{2}$ were more at risk for secondary $\mathrm{PPH}$, which agrees to some extent with a study done in 2013 [9]. Concomitantly, obese women tend to have longer first and second stages of labour compared to non-obese women, which considered one of the risk factors for postpartum haemorrhage. In this study, we observed secondary PPH more in multiparas women, although another study by Mulic-Lutvica et al. in 2009 [10] found that PPH was more common in primiparas women. Other studies $[11,12]$ reported the majority of grand multiparous women developed secondary postpartum haemorrhage. The differences among these study results may be related to geographic and ethnic differences and to the preference among most of the primigravida to deliver by a midwife. The present work revealed a higher incidence of secondary PPH among women who hadn't been booked or had irregular ANC, in agreement with the study by Ajenifuja, Ko et al., 2010 [13]. Anaemia was found to be prevalent in $43.5 \%$ of patients who developed secondary $\mathrm{PPH}$, which was similar to a study by Khalil, Rozhan [14]. Our work observed that 149 of women who developed secondary PPH delivered in the hospital and 51 of women delivered at home, in contrast to a previous study by Jabbar, Shazia; 2019 [15] in which he found that most of the patients who developed secondary PPH delivered at home or in health facilities. This difference may be related to AL-Yarmok's status as a teaching hospital and tertiary centre that receives referral cases from all areas in our country. The time interval between delivery and onset of secondary PPH was 6-10 days for $44.5 \%$ of patients, which is similar to the finding published by Waseeqa Nigeen [16]. A history of primary PPH among women with secondary PPH in our current work was $45.5 \%$, higher than the value cited by Dossou M et al. (19\%), and it has been suggested that immediate PPH is a predictive factor of hysterectomy (4). Signs and symptoms of tachycardia and hypotension (shock) were founded most commonly, and we also observed more hysterectomies in patients who presented with severe hypotension and tachycardia, similar to a study by Kreshna H. M. et al.; 2011 [17], which may be due to patients ignoring bleeding, underestimating the amount of bleeding and delaying care. Those factors led them to endured an emergency hysterectomy to save their life. Fever was the most common symptom that led patients to seek medical advice and it was present in 159 (79\%) of cases. This finding does not agree with the study done by Waseeqa
Nigeen et al. [16]; 2017 in which he found that only fourteen (28\%) of patients had a fever. This variation may be due to most of the patients not taking antibiotics even if needed after vaginal deliveries, increasing the incidence of endometritis; it is well known that fever is one of the symptoms that indicate infection. Maternal haemoglobin was low in most patients who presented with secondary $\mathrm{PPH}$, and Waseeqa Nigeen et al.; 2017, [16] agree with the current study. This low level of haemoglobin is due to a massive amount of blood loss after vaginal delivery until the time of presentation. This study identified 98 (49\%) who needed an admission of more than 5 days, in agreement with a study by Kamrun Nessa et al. conducted on 33 patients with a history of secondary $\mathrm{PPH}$; 24 (73\%) needed an admission of more than 5 days. This finding relates to surgical management and hysterectomies due to delays in seeking care rather than medical treatment, and this aggressive surgical intervention required longer hospitalizations [18]. We found a wide range of treatment modalities for the management of secondary $\mathrm{PPH}$, ranging from medical to surgical, and about 33 (16.5\%) patients responded to conservative management and 47 patients needed vaginal exploration after delivery. A study by Sheikh, Lumaan et al., 2011 [19] evaluated variable types of management protocols, which support our findings. This works described other management options and found that hysterectomy, as a lifesaving procedure, was required for $34.5 \%$ of patients, which was higher than a study done by Kittur et al., 2016 who found that the percentage of patients requiring a hysterectomy was only $6.9 \%$ [20]. This difference may be related to our study criteria, which included only vaginal deliveries, and to geographical variation and to the lack of other available facilities for controlling postpartum haemorrhage; such as embolization, an alternative to a hysterectomy, is not available in our radiological department. In this study, endometritis was the leading cause of secondary PPH among the patients (64\%), followed by retained placental pieces (13.5\%), which is not consistent with Kasap et al. [21] who did a retrospective descriptive study in North India for 6 months and found that retained products of contraception (RPOCs) was the leading cause (72\% of patients) followed by endometritis (20\%) [21]. This difference between our study and the other study might be due to a difference in sample size and our work included only women who delivered vaginally [22]. A limitation of the present study was that it was conducted in a single centre. Despite this limitation, this study presents new information from Iraq regarding secondary postpartum haemorrhage in unscarred uteri.

\section{CONCLUSION}

Endometritis was the most common cause of secondary $\mathrm{PPH}$, and emergency hysterectomy was the management option for most patients. 


\section{RECOMMENDATIONS}

Endometritis should be minimized in hospitals to decrease the risk of hysterectomies and the proper management of haemoglobin post-partum should be enforced.

\section{Conflict of interest}

No author has any potential conflicts of interest.

\section{REFERENCES}

1. Say L, Chou D, Gemmill A, et al. Global causes of maternal death: a WHO systematic analysis. Lancet Glob Health. 2014; 2(6): e323-e333, doi: 10.1016/S2214-109X(14)70227-X, indexed in Pubmed: 25103301.

2. Baldvinsdóttir T, Blomberg M, Lilliecreutz C. Improved clinical management but not patient outcome in women with postpartum haemorrhage-An observational study of practical obstetric team training. PLoS One. 2018; 13(9): e0203806, doi: 10.1371/journal.pone.0203806, indexed in Pubmed: 30256808.

3. Iraha $\mathrm{Y}$, Okada $\mathrm{M}$, Toguchi $\mathrm{M}$, et al. Multimodality imaging in secondary postpartum or postabortion hemorrhage: retained products of conception and related conditions. Jpn J Radiol. 2018; 36(1): 12-22, doi: 10.1007/s1 1604-017-0687-y, indexed in Pubmed: 29052024.

4. Dossou M, Debost-Legrand $A$, Déchelotte $P$, et al. Severe secondary postpartum hemorrhage: a historical cohort. Birth. 2015; 42(2): 149-155, doi: 10.1111/birt.12164, indexed in Pubmed: 25867033.

5. Oyelese Y, Ananth CV. Postpartum hemorrhage: epidemiology, risk factors, and causes. Clin Obstet Gynecol. 2010; 53(1): 147-156, doi: 10.1097/GRF.0b013e3181cc406d, indexed in Pubmed: 20142652.

6. $\mathrm{MH} \mathrm{vL}, \mathrm{O}$ E. Transvaginal Ultrasound-guided Thrombin Injection for the Treatment of Secondary Postpartum Hemorrhage Caused by a Pseudoaneurysm of the Uterine Artery. Journal of Rare Disorders: Diagnosis \& Therapy. 2016; 2(4), doi: 10.21767/2380-7245.100046.

7. Guerado E, Medina A, Mata MI, et al. Protocols for massive blood transfusion: when and why, and potential complications. Eur J Trauma Emerg Surg. 2016; 42(3): 283-295, doi: 10.1007/s00068-015-0612-y, indexed in Pubmed: 26650716.

8. Bul SB, Susan Z, Jahan R, et al. Secondary Postpartum Hemorrhage Following Cesarean Section. Journal of Shaheed Suhrawardy Medical College. 2018; 9(1): 23-25, doi: 10.3329/jssmc.v9i1.37255.

9. Bogaerts A, Witters I, Van den Bergh BRH, et al. Obesity in pregnancy: altered onset and progression of labour. Midwifery. 2013; 29(12): 13031313, doi: 10.1016/j.midw.2012.12.013, indexed in Pubmed: 23427851.

10. Mulic-Lutvica A, Eurenius K, Axelsson O. Uterine artery Doppler ultrasound in postpartum women with retained placental tissue. Acta Obstet
Gynecol Scand. 2009; 88(6): 724-728, doi: 10.1080/00016340902934670, indexed in Pubmed: 19412804

11. Debost-Legrand A, Rivière O, Dossou M, et al. Risk Factors for Severe Secondary Postpartum Hemorrhages: A Historical Cohort Study. Birth. 2015; 42(3): 235-241, doi: 10.1111/birt.12175, indexed in Pubmed: 26032774.

12. Ijaiya MA, Aboyeji AP, Abubakar D. Analysis of 348 consecutive cases of primary postpartum haemorrhage at a tertiary hospital in Nigeria. J Obstet Gynaecol. 2003; 23(4): 374-377, doi: 10.1080/0144361031000119529, indexed in Pubmed: 12881075 .

13. Ajenifuja KO, Adepiti CA, Ogunniyi SO. Post partum haemorrhage in a teaching hospital in Nigeria: a 5-year experience. Afr Health Sci. 2010; 10(1)

14. Khalil RY. Association between Anemia during Pregnancy and post partum hemorrhage and perinatal outcome among women with vaginal Births in slemani maternity teaching hospital. ZANCO J Pure Appl Sci. 2018; 30(4): 65-72.

15. Jabbar S, Perveen S, Kumari R. Secondary Postpartum Haemorrhage: Causes and Management In A Tertiary Care Hospital. Ann Abbasi Shaheed Hosp Karachi Med Dent Coll. 2019; 24(1).

16. Nigeen W, Farooq M, Afzal A, et al. Secondary postpartum haemorrhage in a tertiary care hospital of North India: a retrospective analysis. International Journal of Reproduction, Contraception, Obstetrics and Gynecology. 2017; 6(2): 532, doi: 10.18203/2320-1770.ijrcog20170376.

17. Krishna Hm, Chava M, Jasmine N, et al. Patients with postpartum hemorrhage admitted in intensive care unit: Patient condition, interventions, and outcome. J Anaesthesiol Clin Pharmacol. 2011; 27(2): 192-194, doi: 10.4103/0970-9185.81826, indexed in Pubmed: 21772678.

18. Nessa K, Bari S, Khan S, et al. Causes and management of secondary postpartum haemorrhage in a tertiary medical college hospital in Bangladesh. International Journal of Reproduction, Contraception, Obstetrics and Gynecology. 2017; 6(7): 2694, doi: 10.18203/2320-1770. ijrcog20172896.

19. Sheikh L, Najmi N, Khalid $U$, et al. Evaluation of compliance and outcomes of a management protocol for massive postpartum hemorrhage at a tertiary care hospital in Pakistan. BMC Pregnancy Childbirth. 2011; 11: 28, doi: 10.1186/1471-2393-11-28, indexed in Pubmed: 21489279.

20. Kittur S, D. S. Emergency peripartum hysterectomy- a study in tertiary care centre and medical college in Hubli, North Karnataka, India. International Journal of Reproduction, Contraception, Obstetrics and Gynecology. 2016: 1097-1101, doi: 10.18203/2320-1770. ijrcog20160865.

21. Kasap B, Akbaba E, Öner G, et al. Evaluation of Patients with Postpartum Hemorrhage Patients in a University-Affiliated Tertiary Care Hospital. Haseki Tıp Bülteni. 2016; 54(1): 13-18, doi: 10.4274/haseki.2668.

22. Tihana G, Maja B, Kosjenka D, et al. Secondary postpartum hemorrhage: a review of the literature. 2017; 1(3): 138-40. 